\title{
Percutaneous balloon mitral commissurotomy during pregnancy
}

Mohamed Ben Farhat, Habib Gamra, Fethi Betbout, Faouzi Maatouk, Mourad Jarrar, Faouzi Addad, Mabrouk Tiss, Sonia Hammami, Iheb Chahbani, Rafik Thaalbi

\begin{abstract}
Objective-To evaluate the effectiveness and safety of percutaneous balloon mitral commissurotomy for the treatment of pregnant women with severe mitral stenosis over a period of six years.

Design-Analysis of clinical, haemodynamic, and echocardiographic data before and immediately after the procedure, the pregnancy outcome, and the fate of newborn babies.

Setting-Academic cardiovascular centre in Monastir, Tunisia.

Patients-44 pregnant patients who underwent percutaneous transvenous dilatation of the mitral valve between January 1990 and February 1996. Grade 2 mitral regurgitation was present in two patients and densely calcific valves in three $(7 \%)$.
\end{abstract}

Results-Commissurotomy was successfully achieved in all cases. The total mean (SD) duration of the procedure was 72 (18) minutes and that of fluoroscopy 16 (7) minutes. Left atrial pressure decreased from 28 (10) to 14 (7) $\mathrm{mm} \mathrm{Hg}$, mitral pressure gradient fell from $22(8)$ to 5 (3) $\mathrm{mm}$ Hg. Cardiac output increased from $4 \cdot 8$ $(1.1)$ to $6.3(1.2) 1 / \mathrm{min}$ and Gorlin mitral valve area from $0.96(0.21)$ to $2.4(0.4) \mathrm{cm}^{2}$ (all $\mathrm{P} \ll 0.001$ ). Cross sectional echocardiographic mitral valve area increased from $1.07(0.21)$ to $2.32(0.36) \mathrm{cm}^{2}$. There were no maternal or fetal deaths. Complications included a grade 4 mitral regurgitation in one patient that required early valve replacement. All patients delivered at full term, 42 vaginally and two (5\%) by caesarean section; 41 babies were normal and three whose mothers had the procedure near term were relatively hypotrophic. At a mean follow up of 28 (12) months (range 2 to 26) all children had normal growth.

Conclusions-During pregnancy, balloon mitral commissurotomy is the treatment of choice of severe pliable mitral stenosis in patients who are refractory to medical treatment.

(Heart 1997;77:564-567)

Keywords: balloon mitral commissurotomy; pregnancy

Normal pregnancy is associated with an adaptational circulatory state including primarily a $40-50 \%$ increase in cardiac output and decrease in systemic vascular resistance. ${ }^{1}$ In the presence of severe mitral stenosis, these beneficial changes do not occur despite a dangerous rise in left atrial pressure. The increased blood volume and tachycardia aggravate the venocapillary pulmonary congestion. Thus incipient pulmonary oedema can occur, particularly in the peripartum period. Since the initial description by Inoue et $a l^{2}$ in 1984 of percutaneous transvenous balloon mitral commissurotomy, numerous large series $^{3-12}$ have established the efficacy and safety of this procedure. However, its use during pregnancy remained limited to nearly 100 cases. ${ }^{12-22}$ We report the results of this technique in 44 pregnant women with rheumatic mitral stenosis.

\section{Methods}

PATIENTS

Of 549 consecutive patients who underwent balloon mitral commissurotomy in our department from November 1987 to February 1996, 44 were pregnant ( $8 \%$ of overall group, $11 \%$ of women). Their mean (SD) age was 29 (6) years (range 18 to 43 years). Length of pregnancy varied from 15 to 37 weeks, mean 26 (6) weeks. Forty patients (91\%) were in sinus rhythm and the remaining four were in atrial fibrillation. Four patients had a previous surgical commissurotomy and four others had a previous balloon mitral commissurotomy. Despite medical treatment including bed rest, frusemide, and digoxin (only two patients who had uncontrolled heart rate with digitalis were given atenolol), 15 patients (34\%) remained in New York Heart Association (NYHA) functional class IV and 25 patients $(57 \%)$ in class III. The four remaining patients initially had severe disability that improved to functional class II. Two of them had an echo mitral valve area (MVA) of $1.0 \mathrm{~cm}^{2}$ and $1.2 \mathrm{~cm}^{2}$, respectively. In the two others who had an echo MVA of 1.4 and $1.5 \mathrm{~cm}^{2}$, respectively, the procedure was undertaken because of a history of spontaneous miscarriage during the third trimester of previous pregnancies. In four patients, the procedure had to be performed within $\mathbf{4 8}$ hours of admission because of severe refractory pulmonary oedema.

\section{ECHOCARDIOGRAPHIC STUDY}

Cross sectional, pulsed, colour, and continuous wave Doppler echocardiographic examinations were performed 24 hours before and 24 hours after balloon mitral commissurotomy, and at four to six month intervals of fol- 
Table 1 Haemodynamic results before and immediately after balloon mitral commissurotomy

\begin{tabular}{|c|c|c|c|}
\hline & $\begin{array}{l}\text { Before, } \\
\text { mean (SD) }\end{array}$ & $\begin{array}{l}\text { After, } \\
\text { mean (SD) }\end{array}$ & $P$ values \\
\hline Heart rate (beats/min) & $86(13)$ & $82(10)$ & NS \\
\hline \multicolumn{4}{|l|}{ Pressures $(\mathrm{mm} \mathrm{Hg})$} \\
\hline Mean left atrial & $28(10)$ & $14(7)$ & 0.00001 \\
\hline Mean mitral gradient & $22(8)$ & $5(3)$ & 0.00001 \\
\hline \multicolumn{4}{|l|}{ Pulmonary artery } \\
\hline Systolic & $56(24)$ & $36(16)$ & 0.00001 \\
\hline Diastolic & 29 (11) & $17(9)$ & 0.00001 \\
\hline Mean & $41(18)$ & $25(12)$ & 0.00001 \\
\hline \multicolumn{4}{|l|}{ Aorta } \\
\hline Systolic & $105(10)$ & $107(10)$ & NS \\
\hline Diastolic & $67(7)$ & $68(8)$ & NS \\
\hline Mean & $86(8)$ & $86(9)$ & NS \\
\hline Cardiac index $\left(1 / \mathrm{min} / \mathrm{m}^{2}\right)$ & $3.0(0.69)$ & $3.9(0.77)$ & 0.00001 \\
\hline Mitral valve area $\left(\mathrm{cm}^{2}\right)$ & $0.96(0.21)$ & $2.43(0.43)$ & 0.00001 \\
\hline \multicolumn{4}{|l|}{ Pulmonary vascular resistance $\left(\right.$ dyne.s. $\left.\mathrm{cm}^{-5}\right)$} \\
\hline Total & $710(389)$ & $364(214)$ & 0.00001 \\
\hline Arteriolar & $256(216)$ & $166(156)$ & 0.00001 \\
\hline Systemic vascular resistance (dyne.s. $\mathrm{cm}^{-5}$ ) & $1409(309)$ & $1091(230)$ & 0.00001 \\
\hline
\end{tabular}

low up, using SSH-140 A Toshiba equipment; MVA was determined by planimetry of the mitral orifice in a cross sectional short axis view and by the transmitral pressure half time method. The Wilkins score ${ }^{23}$ was used to evaluate the anatomical features of the mitral valve. Severity of mitral regurgitation was determined by expressing the ratio of colour Doppler maximum regurgitant jet area to left atrial area.

\section{CARDIAC CATHETERISATION AND BALLOON COMMISSUROTOMY TECHNIQUE}

The procedure was approved by the ethics committee of our institution, and informed consent was obtained from the 44 patients and their husbands. During the procedure, the patients' pelvic abdominal area was shielded in order to protect the fetus from radiation. To minimise radiation exposure, left ventriculography was not performed. Fluoroscopy was used only when necessary. The procedure was performed in the fasting state and with premedication ( $10 \mathrm{mg}$ clorazepate intravenously) and local anaesthesia. Right and left sided cardiac catheterisation was performed from the left groin. Heparin was given (100 IU/kg body

Table 2 Characteristics of the four patients in NYHA class II before and after balloon mitral commissurotomy

\begin{tabular}{lllllllll}
\hline Patient & 1 & & 2 & & 3 & & 4 & \\
Echo score & 7 & & 6 & & 6 & & 7 & \\
Echographic mitral valve & Pre & Post & Pre & Post & Pre & Post & Pre & Post \\
$\quad$ area $\left(\mathrm{cm}^{2}\right)$ & $1 \cdot 0$ & $2 \cdot 5$ & $1 \cdot 4$ & $2 \cdot 2$ & $1 \cdot 5$ & $3 \cdot 2$ & $1 \cdot 2$ & $2 \cdot 6$ \\
Left atrial pressure (mm Hg) & Pre & Post & Pre & Post & Pre & Post & Pre & Post \\
& 30 & 10 & 18 & 17 & 35 & 15 & 25 & 10 \\
Mitral pressure gradient & Pre & Post & Pre & Post & Pre & Post & Pre & Post \\
$\quad(\mathrm{mm} \mathrm{Hg})$ & 20 & 3 & 15 & 2 & 28 & 4 & 15 & 4 \\
Cardiac index $\left(\mathrm{ml} / \mathrm{min} / \mathrm{m}^{2}\right)$ & Pre & Post & Pre & Post & Pre & Post & Pre & Post \\
& $2 \cdot 5$ & $2 \cdot 8$ & $2 \cdot 9$ & $3 \cdot 8$ & $4 \cdot 7$ & $5 \cdot 8$ & 3 & $3 \cdot 3$ \\
\hline
\end{tabular}

NYHA, New York Heart Association grade; pre/post, before/after commissurotomy.

Table 3 Characteristics of the three patients with severe valvar calcifications

\begin{tabular}{lllllll}
\hline Patient & 1 & & 2 & & 3 & \\
Echo score & 12 & & 13 & & 14 & \\
Echographic mitral valve area $\left(\mathrm{cm}^{2}\right)$ & Pre & Post & Pre & Post & Pre & Post \\
& $0 \cdot 7$ & $1 \cdot 8$ & 1 & $2 \cdot 1$ & $0 \cdot 5$ & $1 \cdot 8$ \\
Left atrial pressure $(\mathrm{mm} \mathrm{Hg})$ & Pre & Post & Pre & Post & Pre & Post \\
& 41 & 20 & 38 & 20 & 40 & 15 \\
Mitral pressure gradient $(\mathrm{mm} \mathrm{Hg})$ & Pre & Post & Pre & Post & Pre & Post \\
Cardiac index $\left(\mathrm{ml} / \mathrm{min} / \mathrm{m}^{2}\right)$ & 28 & 9 & 35 & 10 & 40 & 6 \\
& Pre & Post & Pre & Post & Pre & Post \\
& $2 \cdot 8$ & $3 \cdot 8$ & $2 \cdot 6$ & $3 \cdot 7$ & 3.0 & 3.6 \\
\hline
\end{tabular}

Pre/post, before/after mitral valve commissurotomy. weight) after transseptal catheterisation. Two Triad-AT balloon catheters (Boston Scientific Corporation, Watertown, MA, USA; balloon diameter 18 and $20 \mathrm{~mm}$ ) were used in 41 patients. The Inoue device (Toray Industries, Tokyo, Japan) was used in three patients.

\section{STATISTICAL ANALYSIS}

Data are reported as a mean (SD). Continuous variables were compared using the Student two tailed $t$ test. A P value of less than 0.05 was considered significant.

\section{Results}

\section{IMMEDIATE RESULTS}

There was no technical failure. The duration of the procedure varied from 54 to $100 \mathrm{~min}$ utes, mean (SD) 72 (18), and the fluoroscopy time was 16 (7) minutes (range 7 to 26). As shown in table 1, major haemodynamic improvement and highly significant increase in MVA from 0.96 to $2.43 \mathrm{~cm}^{2}$ by the Gorlin formula were obtained. MVA, as determined by cross sectional echocardiography, increased from $1.07(0.21)$ to $2.32(0.36) \mathrm{cm}^{2}$, and as determined by the Doppler method it increased from $1.03(0.22)$ to $2.32(0.22) \mathrm{cm}^{2}$. No patient was left with residual mitral stenosis (MVA $<1.5 \mathrm{~cm}^{2}$ ).

Table 2 gives the baseline characteristics and major haemodynamic changes in the four patients who were in NYHA functional class II before balloon mitral commissurotomy. Baseline features and results were very similar to those of the whole group. In patients with severe calcium deposits on fluoroscopy, an acceptable increase in MVA and cardiac index was obtained, as well as a significant decrease in left atrial pressure (table 3). Precommissurotomy grade 2 mitral regurgitationwhich was present in two cases-remained unchanged, whereas MVA, as determined by cross sectional echo, increased to $2 \cdot 3 \mathrm{~cm}^{2}$ in both cases and left atrial pressure decreased to 14 and $16 \mathrm{~mm} \mathrm{Hg}$ respectively. Two other patients developed a grade 2 mitral regurgitation which was well tolerated. There were no deaths or peripheral emboli. Complications included a grade 4 mitral regurgitation in one patient which required early mitral valve replacement, and an incomplete femoral vein thrombosis in another patient, which resolved with heparin treatment. Four patients (9\%) had a trivial to moderate left to right interatrial shunt with a pulmonary to systemic flow ratio $(\mathrm{Qp} / \mathrm{Qs})$ of $<1 \cdot 4: 1$.

\section{POSTCOMMISSUROTOMY COURSE}

All patients, including the one who received early mitral valve replacement, had a substantial functional improvement which allowed discontinuation of diuretics in all but the four patients with grade 2 mitral regurgitation. Digoxin was continued in those four patients and in the four patients with atrial fibrillation. Acenocoumarol was given until the 37 th week of gestation to the four patients in atrial fibrillation and to the patient who received mitral valve replacement; after this it was replaced by 
subcutaneous heparin. The 44 women all had a spontaneous full term delivery, vaginally in 42 and by caesarean section in two for obstetrical reasons. The 44 newborn babies were healthy, without any evidence of fetal abnormality caused by radiation. Mean body weight of the babies was $3.2(0.45) \mathrm{kg}$, range 2.0 to 4.4 . Three women who underwent balloon mitral commissurotomy late in pregnancy (after the 30th week of gestation) delivered hypotrophic babies (body weight between 2 and $2 \cdot 5 \mathrm{~kg}$ ).

At a mean follow up of 30 (16) months (range 6 to 72 ), 40 patients (91\%) remained in functional class I, three patients were in class II, and one patient with a severely calcified valve returned to class IV, with severe mitral stenosis which required mitral valve replacement. Overall, MVA as assessed by cross sectional echo decreased from $2 \cdot 32(0 \cdot 36)$ to $2 \cdot 17$ $(0.40) \mathrm{cm}^{2}(\mathrm{P}<0.05)$. At a mean postpartum follow up of 28 (12) months (range 2 to 66), the 44 infants had shown normal growth and development.

\section{Discussion}

Since the initial description by Inoue et $a l^{2}$ numerous large series have proved the efficacy and safety of balloon mitral commissurotomy as a treatment of rheumatic mitral stenosis. ${ }^{3} 12$

\section{BALLOON MITRAL COMMISSUROTOMY DURING} PREGNANCY

Successful double balloon mitral commissurotomy during pregnancy was first reported in 1988 by Safian et al ${ }^{13}$ and Palacios et al. ${ }^{14}$ The use of this new procedure during pregnancy has remained limited, and among the 11 reports ${ }^{12-22}$ documenting about 100 cases, only one included 19 patients. ${ }^{18}$ For the best of our knowledge, our series is the largest reported with complete pre- and postprocedural haemodynamic assessment. As reported in these other studies, in our series balloon mitral commissurotomy produced impressive haemodynamic improvement including a decrease in left atrial and pulmonary artery pressures, a fall in pulmonary and systemic vascular resistance, and an increase in cardiac output and mitral valve area.

One of the crucial changes that affects the subsequent course of gestation is likely to be the significant increase in cardiac output $(1 \cdot 5$ $1 /$ min in this study). Most of our patients had a pliable mitral valve with mild or no mitral regurgitation, which represent the ideal anatomy for balloon mitral commissurotomy. With the benefit of the experience we have acquired, we broadened our indications to include three patients with a densely calcified mitral valve and two with a pliable mitral valve but with a grade 2 mitral regurgitation. Very satisfactory results were obtained in all those five cases. Other large studies ${ }^{3-12}$ including our own have also reported satisfactory results in many patients with calcific valves. With respect to grade 2 mitral regurgitation, although this remained unchanged in our two patients, we believe that in such cases balloon mitral commissurotomy should be performed with great caution and with adequate surgical back up.

Very few complications have been reported with balloon mitral commissurotomy during pregnancy. New severe mitral regurgitation occurred in only one patient of our series, who underwent a successful prosthetic mitral valve replacement. In one report, one patient had a spontaneous abortion. ${ }^{20}$ Occasionally ${ }^{17} 19$ ominous hypotension requiring administration of drugs and fluids occurred. A left to right interatrial shunt was more common, but it was too small to have any immediate or late consequences. There were no maternal deaths in our series or in the previous reports. ${ }^{12-22}$ In contrast, mortality from surgical closed mitral commissurotomy was as high as $3 \%^{24-26}$ and that from open commissurotomy reached $5 \% .27-30$

\section{EFFECT OF BALLOON MITRAL}

COMMISSUROTOMY ON PREGNANCY OUTCOME Highly significant functional improvement paralleled haemodynamic improvement in all patients: frusemide was discontinued in $90 \%$ of patients and digoxin in $81 \%$. Forty patients returned to class I and four to class II. Uneventful full term delivery was obtained in all patients, vaginally in 42 ; caesarean section was required in only two patients $(5 \%)$ for obstetric reasons. The relative growth retardation in three newborns probably reflected the lateness of the procedure in these cases, but this needs further investigation to be confirmed.

There were no fetal deaths or preterm deliveries in our series. However, in previous studies, three neonatal fatalities have been reported; all three were related to particular circumstances: a premature birth, ${ }^{15}$ an obstetric factor, ${ }^{19}$ and a gemellar pregnancy. ${ }^{20}$ Following surgical closed mitral commissurotomy, ${ }^{24-26}$ the prematurity rate varied from $10 \%$ up to $37 \%$, and fetal mortality ranged from $0 \%$ up to $15 \%$. Open heart commissurotomy carries a higher risk of $20-30 \%$ fetal wastage. ${ }^{27-30}$

Fluoroscopic radiation exposure carries a potential risk to the unborn child. However, the risk is greatly diminished by appropriate and complete abdominal lead shielding, a short radiation exposure time, avoidance of left ventricular angiography, and performance of the procedure after the 14 th week of gestation, when organogenesis has already been achieved. In previous reports, as in our own, no baby had abnormalities related to radiation.

The double balloon technique was used in most of our patients and the Inoue balloon, which was not available in our centre until recently, was used in only three patients, with similar results to the others. The Inoue balloon technique seems to shorten the fluoroscopy time ${ }^{18}$ and therefore appears very attractive in this particular setting. The fluoroscopy time in our series was similar to that reported by Ribeiro et $a l^{17}$ who used the Inoue balloon technique. Patel et $a l^{18}$ reported a shorter fluoroscopy time but they did not 
record the haemodynamic measurements which certainly contribute to the shortening of the procedure. The total radiation dose has sometimes been estimated ${ }^{1319}$ and has always been lower than 0.2 rads, far below the dose at which therapeutic abortion can legally be carried out. It is noteworthy that the 44 infants in this study had normal growth and mental development at an intermediate follow up. Twenty children are now 3 to 5 years old and are in excellent health. As yet, however, the long term outcome in these children remains unknown, since the future late appearance of radiation side effects cannot be excluded, though it must be very unlikely. Griem et al, ${ }^{31}$ in a 20 year follow up study of 1000 women irradiated for radiopelvimetry at much higher doses (15 to $30 \mathrm{mSv}$ ), found no difference in the incidence of cancer in comparison with a control group.

\section{MEDICAL TREATMENT FOR MITRAL STENOSIS DURING PREGNANCY}

Although medical treatment is always recommended as first line therapy of mitral stenosis during pregnancy before considering balloon mitral commissurotomy, the untoward effects of some drugs in this particular setting should be borne in mind.

Diuretics, which are very effective, are known on the other hand to decrease placental perfusion and therefore are not recommended during pregnancy. ${ }^{32}$

$\beta$ Blockers, which can be very beneficial during pregnancy, ${ }^{33}$ also carry some risk, particularly in patients with severe pulmonary hypertension and low cardiac output. Some studies have failed to show any clear benefit of $\beta$ blockers in non-pregnant patients with mitral stenosis, ${ }^{34}{ }^{35}$ while others ${ }^{32}$ have reported serious adverse effects on the fetus and neonate (intrauterine growth retardation, bradycardia, hypoglycaemia, hyperbilirubinaemia) with the use of these agents during pregnancy.

Thus balloon commissurotomy seems to be an excellent alternative to drug treatment. However, until greater experience is acquired, balloon mitral commissurotomy during pregnancy should be confined to patients with severe mitral stenosis who are refractory to optimum medical treatment.

Note added in proof: Since this paper was submitted, we have successfully performed six more balloon mitral commissurotomies during pregnancy.

We thank Jamila Rassas for manuscript preparation

1 Metcalfe J, Ueland K. Maternal cardiovascular adjustments to pregnancy. Prog Cardiovasc Dis 1974;16:363-74.

2 Inoue K, Owaki T, Nakamura T, Kitamura F, Miyamoto N. Clinical application of transvenous mitral commissurotomy by a new balloon catheter. $¥$ Thorac Cardiovasc surotomy by a new ball

3 Vahanian A, Michel PL, Cormier B, Ghanem G, Vitoux B, Maroni JP. Immediate and mid-term results of percutaneous mitral commissurotomy. Eur Heart $\mathcal{f} 1991$ 12(suppl B):84-9.

4 Multicenter experience with balloon mitral commissurotomy: The NHLBI Balloon Valvuloplasty Registry repor on immediate and 30-day follow-up results. Circulation 1992;85:448-6

5 Ruiz CE, Zhang HP, Macaya C, Aleman EH, Allen JW, Lau FYK. Comparison of Inoue single-balloon versus double-balloon technique for percutaneous mitral valvotomy. Am Heart f 1992;123:942-7.

6 Hermann HC, Ramaswamy K, Isner JM, Feldman TE, Caroll JD, Pichard AD, et al. Factors influencing immediate results, complications, and short-term follow-up status after Inoue balloon mitral valvotomy: a North American multicenter study. Am Heart $\mathcal{f} 1992 ; 124$ $160-6$.

7 Cohen DJ, Kuntz RE, Gordon SPF, Piana RN, Safian RD, Mckay RG. Predictors of long-term outcome after percutaneous balloon mitral valvuloplasty. $N$ Engl f Med 1992; 327:1329-35.

8 Rothlisberger C, Essop MR, Skudicky D, Skoularigis J, Wisenbaugh T, Sareli P. Results of percutaneous balloon mitral valvotomy in young adults. $A m \mathcal{f}$ Cardiol 1993;72:73-7.

9 Palacios IF, Tuzcu ME, Weyman AE, Newell JB, Block PC. Clinical follow-up of patients undergoing percutaneous mitral balloon valvotomy. Circulation 1995;91: 671-6.

10 Chen CR, Cheng TO. Percutaneous balloon mitral valvuloplasty by the Inoue technique: a multicenter study of

11 Ben Farhat M, Betbout F, Gamra H, Maatouk F, Ayari M, Cherif A, et al. Results of percutaneous double balloon mitral commissurotomy in one medical center in Tunisia. Am $\mathcal{f}$ Cardiol 1995;76:1266-70.

12 Arora P, Karla GS, Murty GSR, Trehan V, Jolly N, Mohan $\mathrm{JC}$, et al. Percutaneous transatrial mitral commissurotomy: immediate and intermediate results. $\mathcal{F} \mathrm{Am}$ Coll tomy: immediate and in

13 Safian R, Berman A, Sachs B, Diver DJ, Come PC, Baim DS, et al. Percutaneous balloon mitral valvuloplasty in a pregnant women with mitral stenosis. Cathet Cardiovasc Diagn 1988;15:103-8.

14 Palacios I, Block PC, Wilkins T, Rediker DE, Dagget W Percutaneous mitral balloon valvotomy during pregnancy in a patient with severe mitral stenosis. Cathet Cardiovasc Diagn 1988;15:109-11.

15 Mangione JA, Zuliani MF, Del Castillo JM, Nogueira EA, Arie S. Percutaneous double balloon mitral valvuloplasty in pregnant women. Am f Cardiol 1989;64:99-102.

16 Ben Farhat $M$, Maatouk F, Betbout F, Ayari M, Brahim H, Souissi $M$, et al. Percutaneous balloon mitral valvuloplasty in eight pregnant women with severe mitral stenosis. purty in eight pregnant women

17 Ribeiro PA, Fawzi ME, Awad M, Dunn B, Duran CG. Balloon valvotomy for pregnant patients with severe pliable mitral stenosis using the Inoue technique with total abdominal and pelvic shielding. Am Heart $\mathcal{f}$ 1992;124: 1558-62.

18 Patel JJ, Mitha AS, Hassen F, Patel N, Naidu R, Chetty S, et al. Percutaneous balloon mitral valvotomy in pregnant patients with tight pliable mitral stenosis. Am Heart $\mathcal{f}$ 1993;125:1106-9.

19 Iung B, Cormier B, Elias J, Michel PL, Nallet O, Porte JM, et al. Usefulness of percutaneous balloon commissurotomy for mitral stenosis during pregnancy. Am $\mathcal{F}$ Cardiol 1994;73:398-400.

20 Esteves CA, Ramos AIO, Braga SLN, Harrison JK, Sousa JE. Effectiveness of percutaneous balloon mitral valvotomy during pregnancy. Am $\mathcal{f}$ Cardiol 1991;68:930-4.

21 Smith R, Brender D, Credie M. Percutaneous transluminal balloon dilatation of the mitral valve in pregnancy. $\mathrm{Br}$ Heart f 1989;61:551-3.

22 Drobinski G, Fraboulet P, Montalescot G, Moussallem N, Goulte R, Artigou JY, et al. Valvuloplastie mitrale au quatrième mois de grossesse. Protection foetale par un manteau de plomb. Arch Mal Coeur 1991;84:249-51.

23 Wilkins GT, Weyman AE, Abascal VM, Block PC Palacios IF. Percutaneous balloon dilatation of the mitral valve : an analysis of echocardiographic variables related to outcome and the mechanism of dilatation. Br Heart $f$ outcome and the

24 Knapp RC, Ardin LI. Closed mitral valvulotomy in pregnancy. Clin Obstet Gynecol 1968;11:978-91.

25 El Maraghy M, Abou Senna I, El Tewehy F, Bassioni M, Ayoub A, El Sayed H. Mitral valvotomy in pregnancy. Am $\mathcal{F}$ Obstet Gynecol 1983;145:708-10.

26 Vosloo S, Reichart B. The feasibility of closed mitral valvotomy in pregnancy. $\mathcal{F}$ Thorac Cardiovasc Surg 1987;93: 675-9.

27 Zitnik RS. Pregnancy and open heart surgery. Circulation 1969;39:1257-62.

28 Szekely P, Snaith L. The place of cardiac surgery in the management of the pregnant women with heart disease. $\mathcal{F}$ Obstet Gynecol 1973;70:69-77.

29 Becker RM. Intracardiac surgery in pregnant women. Ann Thorac Surg 1983;36:453-8.

30 Bernal JM, Mitralles PJ. Cardiac surgery with cardiopulmonary bypass during pregnancy. Obstet Gynecol Surv 1986;41:1-6.

31 Griem ML, Meier P, Dobben GD. Analysis of the morbidity and mortality of children irradiated in fetal life. Radiology 1967;88:347-9.

32 Widerhorn J, Rubin JN, Frishman WH, Elkayam U. Cardiovascular drugs in pregnancy. Cardiol Clin 1987;5: 651-74.

33 Al Kasab SM, Sabag T, AL Zaibag M, Awaad M, Al Bitar I, Halim AM, et al. Beta-adrenergic receptor blockade in he management of pregnant women with mitral stenosis. Am $\mathcal{F}$ Obstet Gynecol 1990;163:37-40.

34 Wisenbaugh T, Essop R, Middlemost S, Skoularigis J, Othlisberger C, Skudicky D, et al. Pulmonary hypertension is a contraindication to beta blockade in patients with severe mitral stenosis. Am Heart f 1993;125:786-90. 35 Stoll BC, Ashcom TL, Johns JP, Johnson JE, Rubal BJ. Effects of atenolol on rest and exercise hemodynamics in patients with mitral stenosis. Am $\mathcal{F}$ Cardiol 1995;75: 482-4. 